\title{
Balkanologie
}

Balkanologie Revue d'études pluridisciplinaires

Vol. XII, $n^{\circ} 1$ | 2010

Volume XII Numéro 1

\section{Basciani (Alberto), D’Alessandri (Antonio), Balcani 1908. Alle origini di un secolo di conflitti}

Trieste : Beit, 2010, 221 p.

Fabrice Jesné

\section{CpenEdition}

\section{Journals}

Édition électronique

URL : http://journals.openedition.org/balkanologie/2161

DOI : 10.4000/balkanologie. 2161

ISSN : 1965-0582

Éditeur

Association française d'études sur les Balkans (Afebalk)

Référence électronique

Fabrice Jesné, « Basciani (Alberto), D’Alessandri (Antonio), Balcani 1908. Alle origini di un secolo di conflitti », Balkanologie [En ligne], Vol. XII, n 1 | 2010, mis en ligne le 02 avril 2010, consulté le 17 décembre 2020. URL : http://journals.openedition.org/balkanologie/2161 ; DOI : https://doi.org/ 10.4000/balkanologie.2161

Ce document a été généré automatiquement le 17 décembre 2020.

(C) Tous droits réservés 


\section{Basciani (Alberto), D’Alessandri (Antonio), Balcani 1908. Alle origini di un secolo di conflitti}

Trieste : Beit, 2010, 221 p.

Fabrice Jesné

\section{RÉFÉRENCE}

Alberto Basciani, Antonio D'Alessandri, Balcani 1908. Alle origini di un secolo di conflitti,

Trieste : Beit, 2010, $221 \mathrm{p}$.

1 Deux colloques internationaux se sont tenus à Paris et à Rome à l'occasion des 100 ans de la crise balkanique de $1908^{1}$. Les actes de la manifestation italienne ont été publiés au début de l'année 2010 par la maison triestine Beit, et font l'objet du présent compterendu.

Comme son homologue parisienne, la rencontre romaine entendait insister sur l'importance de l'analyse historique pour comprendre les enjeux actuels de l'intégration des Balkans à l'Union européenne. Entre 1981 et 2007, trois élargissements ont en effet permis à quatre pays balkaniques - la Grèce, la Slovénie, la Roumanie et la Bulgarie - d'entrer dans l'organisation supranationale, alors que les Balkans occidentaux se trouvent encore dans une phase de fragmentation illustrée par les indépendances du Monténégro en 2006 et du Kosovo en 2008. Cent ans plus tôt, les provinces ottomanes de Bosnie et d'Herzégovine étaient annexées par l'AutricheHongrie, qui les occupait depuis 1878.

Les contributions rassemblées sous la direction d'Alberto Basciani et Antonio D'Alessandri, de l'Université de Rome 3, apportent une grande variété de points de vue sur la crise européenne qui découla des événements balkaniques. Une introduction de Francesco Guida en rappelle la chronologie précise et les enjeux : la révolution jeuneturque de l'été 1908 provoqua d'abord une crise régionale, la principauté de Bulgarie 
profitant de l'occasion pour se déclarer indépendante de son ancien suzerain ottoman. Les secteurs les plus va-t-en guerre du gouvernement et de l'État-major austrohongrois firent également un pas décisif dans une région où s'entrecroisaient les intérêts économiques et politiques des grandes puissances européennes. Ce coup de force bouleversa l'équilibre des alliances sur le continent, exacerbant notamment la méfiance de la Russie et de l'Italie envers l'Autriche-Hongrie. Le contenu de l'ouvrage confirme l'importance de l'analyse multilatérale et multiscalaire en matière d'études balkaniques : les contributions de Catherine Horel et Viktor Avdeev se concentrent sur l'activité diplomatique des deux principales puissances d'Europe orientale, l'AutricheHongrie et la Russie. En écho à ce grand jeu, on trouve une analyse des stratégies des acteurs plus modestes que sont l'Italie, la Roumanie et la Serbie sous la plume de Rudolf Dinu et Massimo Bucarelli. Le recueil accorde en outre une grande attention aux acteurs infra-étatiques que sont les partis et les élites politiques (Francisco Veiga, Ignác Romsics et Andrej Pantev pour les cas turc, hongrois et bulgare), les opinions publiques (notamment Adriano Roccucci sur l'impact de la crise en Italie) et les mouvements nationalistes, qui sont présentés dans leurs déclinaisons bosniaque, macédonienne et albanaise par Vojislav Pavlović, Alberto Basciani et Antonio D'Alessandri. La contribution du géopoliticien Eric Robert Terzuolo clôt le recueil par un retour en 2008, autour des modalités problématiques du State building au Kosovo.

Le caractère polyphonique de l'analyse se lit dans la variété des sources utilisées. Si les auteurs font un usage fréquent des sources diplomatiques éditées, plusieurs d'entre eux présentent une documentation directement tirée des archives gouvernementales russes, italiennes, roumaines et françaises. À ces sources d'archives s'ajoutent les mémoires et les correspondances des diplomates, des journalistes et des acteurs politiques dont l'activité contribua à donner un retentissement international à l'un des derniers soubresauts de l'Empire ottoman.

\section{NOTES}

1. 1908. La crise de Bosnie dans le contexte européen, cent ans après, colloque international, Paris, 26-27/09/08; I Balcani dalla crisi del 1908 al processo di integrazione nell'Unione Europea, colloque international, Rome, 27-28/11/08.

\section{AUTEURS}

\section{FABRICE JESNÉ}

Membre de l'École française de Rome 